\title{
Commentary: Fenestration in static malperfusion for acute type $B$ aortic dissection: Teamwork can be the Holy Grail, but concerns remain
}

\author{
Ourania Preventza, MD
}

\footnotetext{
From the Division of Cardiothoracic Surgery, Michael E. DeBakey Department of Surgery, Baylor College of Medicine, Houston, Tex; and Department of Cardiovascular Surgery, Texas Heart Institute, Houston, Tex. Disclosures: Author has nothing to disclose with regard to commercial support.

Received for publication Sept 3, 2019; revisions received Sept 3, 2019; accepted for publication Sept 3, 2019; available ahead of print Sept 23, 2019.

Address for reprints: Ourania Preventza, MD, Division of Cardiothoracic Surgery, Michael E. DeBakey Department of Surgery, Baylor College of Medicine, One Baylor Plaza, BCM 390, Houston, TX 77030 (E-mail: preventz@bcm.edu).

J Thorac Cardiovasc Surg 2020;160:1162-3

0022-5223/\$36.00

Copyright (c) 2019 by The American Association for Thoracic Surgery

https://doi.org/10.1016/j.jtcvs.2019.09.034
}

Early mortality for acute type B aortic dissection remains significant, ${ }^{1}$ and malperfusion is often implicated in poor early outcomes. Malperfusion after the initial acute postdissection period is uncommon and can indicate a new dissection process, especially when accompanied by severe back pain.

In this issue of the Journal, Norton and colleagues ${ }^{2}$ report their 20-year, single-center experience with 182 patients with spontaneous acute type $\mathrm{B}$ aortic dissection and suspected malperfusion. The authors suggest that endovascular fenestration and stenting can resolve dynamic and static malperfusion, producing favorable short- and long-term outcomes. Their overall in-hospital mortality rate was $7.7 \%$ over 20 years, $11.3 \%$ in the first decade (19962007), 3.5\% in the second decade (2008-2018), and $0 \%$ in the last 8 years. There is no control group of patients undergoing thoracic endovascular aortic repair, and no earlyor long-term imaging data are reported, which makes it difficult to draw conclusions about the safety and efficacy of their technique. Nevertheless, the outcomes are noteworthy for a very sick patient population.

The authors must be congratulated for their laudable results, which come from an outstanding aortic team and center. They emphasize the learning curve and working together with interventional radiology. Other factors, such as evolution of their technique of fenestration/stenting, better management in the intensive care unit, endovascular stent grafting for impending rupture, treating suspected malperfusion in acute type B dissection as an angiographic emergency, and increasing experience with managing the disease, no doubt contributed to the high rate of good outcomes.

Whereas dynamic malperfusion can be resolved with thoracic endovascular stent grafting (thoracic endovascular aortic repair), static malperfusion can be challenging to treat. Its various manifestations include intestinal, renal, splenic, hepatic, extremity, and spinal cord ischemia. The

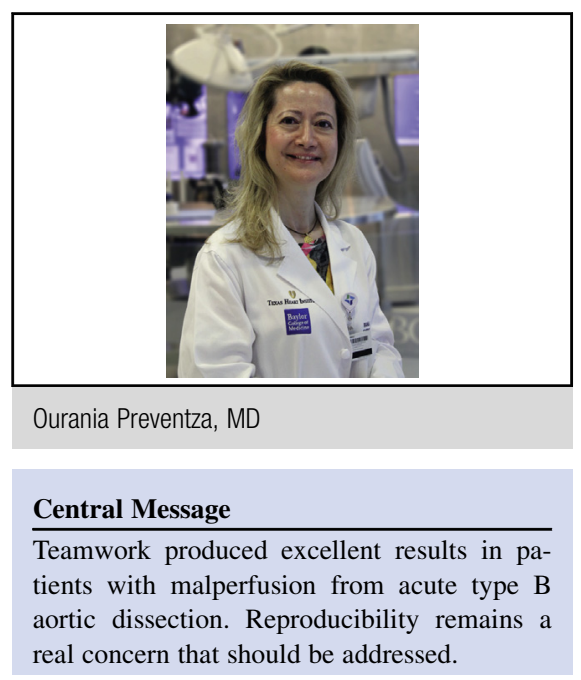

See Article page 1151 .

visceral vessels are the most commonly involved. Endovascular treatment is preferred to open surgery, when possible, to resolve the malperfusion, although no trials have yet compared endovascular and open surgical interventions. Fenestration between the true and false lumens can be performed with various techniques, with the goal of equalizing the systolic pressures between the 2 chambers and decompressing the pressurized false lumen; thus, fenestration is indicated for static malperfusion.

To this end, Norton and colleagues used the technique of tearing the septum by ballooning and stenting. The fenestration can also be created with various needles or the back end of a small 0.014- or 0.018-inch wire. Another method is the scissors technique ${ }^{3}$ described almost 2 decades ago, in which stiff wires are placed in the true and false lumens of the same artery, and a single long sheath is advanced over both wires to divide the septum. Another alternative is the pull-through-and-through snare technique, in which a wire from one femoral artery is delivered via the septum to the other femoral artery; pulling the wire creates a fenestration. Additional stenting may be required; selfexpanding stents are preferable, because balloonexpandable stents could be crushed by the mobile septum. Unpredictable changes in the intimal flap anatomy and dramatic alterations of flow dynamics, intimal dehiscence, and aorto-aortic intussusception have been reported with the 
various fenestration techniques and remain a serious concern. Potentially, future endovascular technology and better imaging could resolve these issues.

In addition, even though the unique collaboration of the surgical team with the interventional radiology team at this spectacular aortic center has to be commended, concerns about the reproducibility of these results remain, especially at lower-volume centers. Nonetheless, this group's emphasis on teamwork is praiseworthy.

\section{References}

1. Suzuki T, Mehta RH, Ince H, Nagai R, Sakomura Y, Weber F, et al. Clinical profiles and outcomes of acute type B aortic dissection in the current era: lessons from the International Registry of Aortic Dissection (IRAD). Circulation. 2003; 108(suppl 1):II312-7.

2. Norton E, Williams D, Kim K, Khaja M, Wu X, Patel HJ, et al Management of acute type B aortic dissection with malperfusion via endovascular fenestration/stenting. J Thorac Cardiovasc Surg. 2020;160: 1151-61.e1.

3. Beregi JP, Prat A, Gaxotte V, Delomez M, McFadden EP. Endovascular treatment for dissection of the descending aorta. Lancet. 2000;356:482-3. 